\title{
Nitrogênio e promotor de crescimento: efeitos no crescimento e desenvolvimento do algodão colorido verde ${ }^{1}$
}

\author{
Maria M. de Lima ${ }^{2}$, Carlos A. V. de Azevedo ${ }^{3}$, Napoleão E. de M. Beltrão ${ }^{4}$, \\ José Dantas Neto ${ }^{3}$, Cira B. Gonçalves ${ }^{3}$ \& Claudia G. da F. Santos ${ }^{3}$
}

\begin{abstract}
RESUMO
Objetivou-se, com este trabalho, quantificar os efeitos dos fatores adubação nitrogenada e promotor de crescimento aplicado nas sementes sobre o crescimento e desenvolvimento do algodão colorido verde. O experimento foi conduzido em casa-de-vegetação pertencente ao Centro Nacional de Pesquisa do Algodão (Embrapa-CNPA), onde o promotor de crescimento Stimulate ${ }^{\circledR}$ foi aplicado nas doses de 10 e $17 \mathrm{~mL}$ por $0,5 \mathrm{~kg}$ de sementes e o $\mathrm{N}$ em cobertura nas doses de $0,80,160$ e $240 \mathrm{~kg} \mathrm{ha}^{-1}$. O delineamento experimental foi em blocos ao acaso com nove tratamentos e três repetições em esquema fatorial $2 \times 4+1$. Estimaram-se as variáveis relativas ao crescimento (altura de planta, diâmetro do caule e área foliar) e ao desenvolvimento (aparecimento do primeiro botão floral, da primeira flor e abertura do primeiro capulho). Verificou-se que o promotor de crescimento Stimulate ${ }^{\circledR}$ não alterou o crescimento do algodoeiro herbáceo nem interagiu com o $\mathrm{N}$ aplicado no meio edáfico. Independentemente do fator dose do promoter de crescimento, $\mathrm{o}$ nitrogênio promoveu um decréscimo linear significante na precocidade das plantas e aumentou o crescimento.
\end{abstract}

Palavras-chave: algodoeiro herbáceo, precocidade, adubação

\section{Nitrogen and growth promoter: Effects on growth and development of green fiber cotton}

\begin{abstract}
This research had the objective of quantifying the effects of nitrogen manuring and growth promoter applied in the seeds on growth and development of cotton of green fiber. The experiment was conducted in greenhouse conditions at the National Center of Cotton Research (EMBRAPA-CNPA), where the growth promoter Stimulate ${ }^{\circledR}$ was applied in doses of 10 and $17 \mathrm{~mL}$ per $0.5 \mathrm{~kg}$ of seeds and the nitrogen topdressing in doses of $0,80,160$ and $240 \mathrm{~kg} \mathrm{ha}^{-1}$. The experimental design was in randomized blocks with nine treatments and three replications in a factorial scheme of $4 \times 2+1$. The variables related to growth (plant height, stem diameter and leaf area) and to development (emergence of first flower button and of first flower and opening of first cotton boll) were analyzed. It was verified that the Stimulate ${ }^{\circledR}$ growth promoter did not alter the growth of the herbaceous cotton as well as did not interact with the nitrogen applied in the edaphic medium. Independent of the growth promoter dose, the nitrogen promoted a significant linear decrease in the precocity of the plants and increased the growth.
\end{abstract}

Key words: herbaceous cotton, precocity, manuring

1 Artigo extraído da Dissertação de Mestrado do primeiro autor

2 Rua Santo Antônio, 736, Santo Antônio, CEP 58103-355, Campina Grande, PB. Fone: (83) 3362 1586. E-mail: madda-lima@hotmail.com

${ }^{3}$ UAEA/UFCG. Av. Aprígio Veloso, 882, Bodocongó, CEP 58109-970, Campina Grande, PB. Fones: (83) 3310 1056; (83) 33101373 . E-mails: cazevedo@deag.ufcg.edu.br; zedantas@deag.ufcg.edu.br; cirabg@bol.com.br; cgfs@bol.com.br

${ }^{4}$ Embrapa Algodão. Rua Osvaldo Cruz, 1143, Centenário, CEP 58107-720, Campina Grande, PB. Fone: (83) 3315 4300. E-mail: nbeltrão@cnpa.embrapa.br 


\section{INTRODUÇÃO}

Atualmente, o algodão é uma das dez principais culturas produtora de fibra, óleo e proteínas ocupando, no Brasil, uma área anual superior a 33 milhões de hectares, média dos últimos 50 anos; esta fibra veste quase metade da humanidade, transformando-se em tecidos brancos e coloridos, via tingimento. Recentemente, através de pesquisas realizadas nos Estados Unidos e no Brasil, além de outros países, como Israel, tem-se obtido cultivares de fibras naturalmente coloridas (ICAC, 2000; CONAB, 2004).

Dentre os elementos essenciais, o nitrogênio é o extraído em maior quantidade pelo algodoeiro, além de necessário para o crescimento e desenvolvimento da planta, especialmente dos órgãos vegetativos; e estimula o crescimento e o florescimento, regulariza o ciclo da planta, aumenta a produtividade e melhora o comprimento e a resistência da fibra, quando aplicado em dosagens adequadas (Beltrão, 1999).

Furlani \& Buzetti (2001) afirmam que quando se efetuou a aplicação de nitrogênio aos 30 dias após a emergência das plantas, as dosagens de 40 e $70 \mathrm{~kg} \mathrm{ha}^{-1}$ de $\mathrm{N}$ propiciaram os maiores valores de altura de plantas quando comparados com aquele verificado para a dosagem de $30 \mathrm{~kg} \mathrm{ha}^{-1}$ de $\mathrm{N}$.

A mistura de dois ou mais biorreguladores com outras substâncias (aminoácidos, nutrientes, vitaminas), é denominada bioestimulante ou estimulante vegetal (Castro \& Vieira, 2001). Este produto químico pode, em função de sua composição, concentração e proporção das substâncias, incrementar o crescimento e o desenvolvimento vegetal, estimulando a divisão celular, diferenciação e o alongamento das células e também, aumentar a absorção e a utilização de água e nutrientes pelas plantas; é especialmente eficiente quando aplicado com fertilizantes foliares e ainda compatíveis com defensivos (Vieira \& Castro, 2002).

Conforme Vieira (2001), o estudo das variáveis confirmam que a concentração de $1,2 \mathrm{~mL}$ de "Stimulate ${ }^{\circledR}$ " promoveu o máximo comprimento de coleóptilo das plântulas de arroz, de $3,0 \mathrm{~cm}$, superando em $18,0 \%$ o comprimento verificado na concentração controle. O máximo de emergência de plântulas de arroz em areia aos 7 DAS de 45,4\%, foi obtida na concentração de $1,5 \mathrm{~mL}$ de "Stimulate ${ }^{\circledR}$ ", a qual superou em $10,2 \%$ a emergência registrada no controle. Para as concentrações avaliadas superiores a 2,0 mL de Stimulate ${ }^{\circledR}$.

A aplicação de $1,9 \mathrm{~mL}$ por $0,5 \mathrm{~kg}$ de Stimulate ${ }^{\circledR}$, nas plantas de arroz provocou a máxima velocidade de crescimento radicular vertical de $5,7 \mathrm{~cm} \mathrm{~d}^{-1}$, sendo 13,0 o incremento sobre a velocidade verificada no controle. Já a aplicação de 2,8 mL por $0,5 \mathrm{~kg}$ de Stimulate ${ }^{\circledR}$, causou o máximo de crescimento radicular vertical de $28,7 \mathrm{~cm}$ nos sistemas radiculares das plantas de arroz, com 14,2\% de incremento em comparação à concentração controle. O comprimento total do sistema radicular das plantas de arroz, recebeu incremento de $37,7 \%$, registrado na concentração de $2,3 \mathrm{~mL}$ de Stimulate ${ }^{\circledR}$, com $189,4 \mathrm{~cm}$ de raízes, em relação ao controle com 137,4 cm (Vieira, 2001).

A cultivar BRS verde foi lançada pela EMBRAPA (2002) e, como se trata de um novo genótipo, não há informações sobre seu comportamento, no tocante a uma resposta à adu- bação nitrogenada e aos promotores de crescimento. A cultivar BRS Verde é geneticamente semelhante a cultivar CNPA 7H, que nos últimos cinco anos foi a mais plantada no Nordeste do Brasil, em especial pelos pequenos produtores ligados à agricultura familiar, diferindo apenas por um único gene, o que promove a fibra de cor verde, que veio da cultivar norte-americana, A. Green (Carvalho et al., 2002), respondendo bem à adubação nitrogenada em diversos ambientes.

Objetivou-se, com este trabalho, quantificar os efeitos de adubação nitrogenada e do promotor de crescimento aplicado nas sementes sobre o crescimento e desenvolvimento do algodoeiro de fibra verde.

\section{MATERIAL E MÉTODOS}

O experimento foi conduzido em condições de casa-devegetação, pertencente ao Centro Nacional de Pesquisa do Algodão (CNPA-EMBRAPA), na cidade de Campina Grande, PB, localizada na zona Centro Oriental do Estado da Paraíba, no Planalto da Borborema, cujas coordenadas geográficas são latitude sul $7^{\circ} 13^{\prime} 11$ ”, longitude oeste 35 53' 31” W. Grw., e altitude 547,56 m, instalado em 29/ 01/2003; tendo como unidade experimental vasos plásticos de aproximadamente $25 \mathrm{~L}$, em número de 27 , de cor prata fosca, tendo-se em vista amenizar os efeitos dos raios solares refletidos por esta cor.

Cada unidade experimental recebeu cerca de $25 \mathrm{~L}$ de solo (coletado da camada superficial 0-30 cm), que foi umedecido até aproximadamente a capacidade de campo, usando-se água de abastecimento; no fundo dos vasos foram feitos dois furos em extremidades opostas, por onde o excesso da água foi drenado.

A profundidade da cova foi de $3 \mathrm{~cm}$ e a adubação aplicada em um sulco tipo meia lua, a $2 \mathrm{~cm}$ de profundidade. Cada unidade experimental recebeu oito sementes, tendo a germinação ocorrido 5 dias após a semeadura, com o aparecimento de 8 plântulas por vaso. O desbaste se deu aos vinte dias após a emergência deixando-se uma plântula por vaso, colhendo-se a de melhor aparência, que foi monitorada durante todo o ciclo fenológico da cultura (140 dias).

A aplicação do Stimulate ${ }^{\circledR}$ foi em dosagem única nas se-

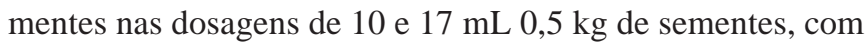
o auxílio de uma seringa de $1 \mathrm{~mL}$; o produto foi colocado nas sementes após diluição em água; as sementes ficaram imersas na solução pelo período de 30 min antes do plantio. Realizaram-se duas aplicações de nitrogênio em dosagens iguais (a metade da dosagem total), em que a primeira foi feita na fase de botão floral aos 34 DAE (dias após emergência) e a segunda na fase de floração, aos 51 DAE.

Adotou-se um delineamento experimental em blocos ao acaso com três repetições, em esquema fatorial 2 x $4+1$, sendo os fatores duas dosagens de promotor de crescimento

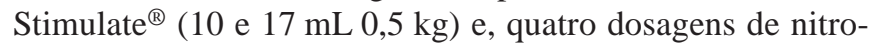
gênio $\left(0,80,160\right.$ e $240 \mathrm{~kg} \mathrm{ha}^{-1}$ de $\left.\mathrm{N}\right)$ resultando em nove tratamentos, incluindo uma testemunha que não recebeu aplicação de $\mathrm{N}$ nem de Stimulate ${ }^{\circledR}$. O Stimulate ${ }^{\circledR}$ é constituído 
de ácido indolbutírico (auxina) 0,005\%, cinetina (citocinina) 0,009\% e ácido giberélico 0,005\%.

Foi utilizado o substrato de um solo de textura arenosa, proveniente do município de Lagoa Seca, PB, classificado como Neossolo Regolítico, anteriormente denominado Regossolo. O solo foi coletado nas instalações da Empresa Estadual de Pesquisa Agropecuária (EMEPA) e caracterizado, química e fisicamente, na EMBRAPA Algodão e no Laboratório de Irrigação e Salinidade do Departamento de Engenharia Agrícola (UFCG). As análises químicas do solo e as características físicas estão apresentadas na Tabela 1.

Tabela 1. Características químicas e físico-hídricas do solo da área experimental

\begin{tabular}{lcc}
\hline Características & Unidade & Valor \\
$\mathrm{pH}$ em água (1:25) & - & 5,5 \\
$\mathrm{P}$ & $\mathrm{mg} \mathrm{dm}^{-3}$ & 3,81 \\
$\mathrm{~K}$ & $\mathrm{mmol}_{\mathrm{c}} \mathrm{dm}^{-3}$ & 0,010 \\
$\mathrm{Ca}$ & $\mathrm{mmol}_{\mathrm{c}} \mathrm{dm}^{-3}$ & 13,0 \\
$\mathrm{Mg}$ & $\mathrm{mmol}_{\mathrm{c}} \mathrm{dm}^{-3}$ & 6,0 \\
$\mathrm{AI}$ & $\mathrm{mmol}_{\mathrm{c}} \mathrm{dm}^{-3}$ & 1,0 \\
$\mathrm{M} 0$ & $\mathrm{~g} \mathrm{~kg}^{-1}$ & 12,08 \\
Areia & $\mathrm{g} \mathrm{kg}^{-1}$ & 766,5 \\
Silte & $\mathrm{g} \mathrm{kg}^{-1}$ & 86,8 \\
Argila & $\mathrm{g} \mathrm{kg}^{-1}$ & 146,7 \\
Densidade & $\mathrm{kg} \mathrm{m}^{-3}$ & 1,52 \\
Capacidade de campo & $\mathrm{cm}^{3} \mathrm{~cm}^{-3}$ & 0,00526 \\
Ponto de murcha permanente & $\mathrm{cm}^{3} \mathrm{~cm}^{-3}$ & 0,00244 \\
\hline
\end{tabular}

Ao solo foi incorporado composto orgânico, na proporção de $5 \mathrm{~kg}$ para $100 \mathrm{~kg}$ de solo, que apresentava a seguinte composição química: $\mathrm{pH}=8,6\left(\mathrm{H}_{2} \mathrm{O} 1: 2.5\right) ; \mathrm{N}=0,56$ $\left(\right.$ dag kg-1); K = 1,19 $\left(\right.$ dag kg $\left.^{-1}\right) ; \mathrm{P}=0,58($ dag kg-1 $) ; \mathrm{Ca}=0,83$ $\left(\right.$ dag $\left.{ }^{-1}\right) ; M g=2,22\left(\right.$ dag kg $\left.^{-1}\right)$.

O fósforo e o potássio foram aplicados por ocasião do plantio nas doses de 80 e $60 \mathrm{~kg} \mathrm{ha}^{-1}$ de $\mathrm{P}_{2} \mathrm{O}_{5}$ e $\mathrm{K}_{2} \mathrm{O}$, respectivamente. Utilizaram-se, como fonte para fósforo e potássio, o superfosfato triplo $\left(42 \% \mathrm{P}_{2} \mathrm{O}_{5}\right)$ e o cloreto de potássio $(62 \%$ $\mathrm{K}_{2} \mathrm{O}$ ) e para o nitrogênio o sulfato de amônio (20\% N).

A variedade BRS Verde foi utilizada devido a sua adequabilidade para o plantio de sequeiro, no semi-árido Nordestino, em razão da incidência de doenças foliares e de solo ser baixa nesta região. A água usada na irrigação das unidades experimentais foi a de abastecimento do município de Campina Grande, PB.

Avaliaram-se:

a) o crescimento: altura de plantas, diâmetro caulinar e área foliar. As determinações da altura de plantas foram feitas em intervalos de 20 dias, utilizando-se de uma régua e se medindo a partir do colo da planta até o ponto de inserção da última folha. Com a utilização de um paquímetro obteve-se o diâmetro do caule, a $1 \mathrm{~cm}$ do colo da planta;

b) o desenvolvimento: aparecimento do primeiro botão floral, da primeira flor e abertura do primeiro capulho.

As variáveis da cultura foram computadas através da análise de variância, utilizando-se o teste $\mathrm{F}$ a nível de 5 e 1\% de probabilidade, conforme Gomes (1985). Para as dosagens de nitrogênio e do regulador de crescimento, realizaram-se análises de regressão e o teste de Tukey, de acordo com Banzatto \& Kronka (1995). O programa empregado nas análises estatísticas foi o SAS versão 8.2 (SAS/STAT, 2000).

\section{RESULTADOS E DISCUSSÃO}

O crescimento das plantas ao longo do ciclo, retratado pelas variáveis altura de planta e diâmetro do caule é mostrado nas Figuras 1 (altura) e 2 (diâmetro). Constatou-se que as dosagens utilizadas do promotor de crescimento Stimulate ${ }^{\circledR}$ não influenciaram tais variáveis de maneira significativa, como pode ser visto nas Figuras 1 e 2, referentes a altura e ao diâmetro caulinar com suas respectivas equações de regressão nas Tabelas 2 e 3, não apresentando efeitos no crescimento das plantas para a cultivar em questão nas condições ambientais onde o genótipo em tela foi colocado para crescer e se desenvolver.

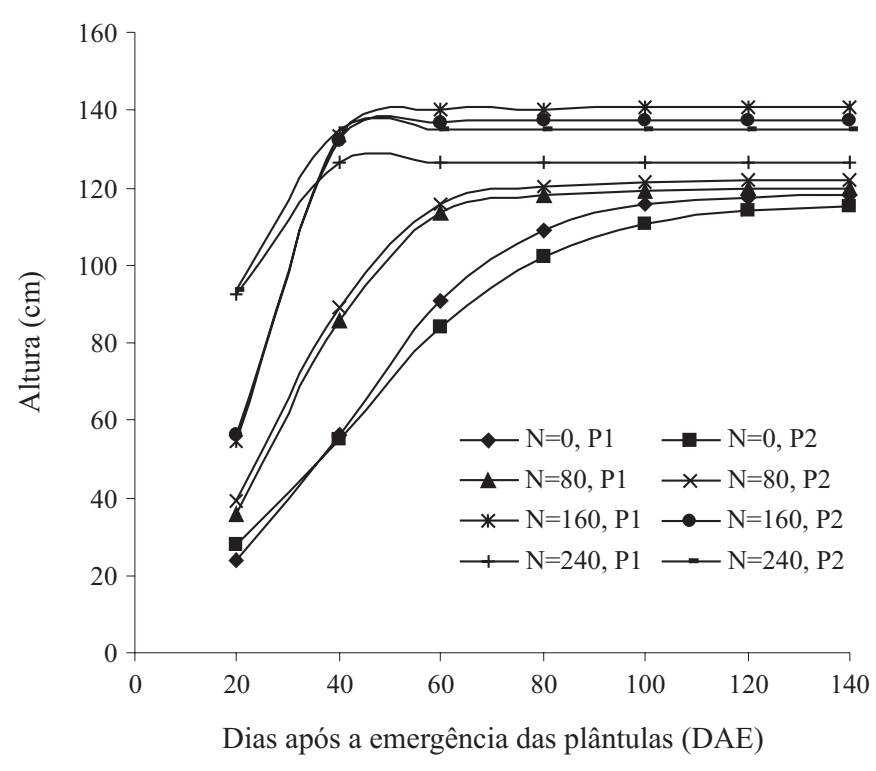

Figura 1. Altura de planta em função do tempo, para as dosagens de 0,80 , 160 e $240 \mathrm{~kg} \mathrm{ha}^{-1}$ de $\mathrm{N}$ e as dosagens do Stimulate ${ }^{\circledR}$ de $10 \mathrm{~mL}$ (P1) por $0,5 \mathrm{~kg} \mathrm{ha}^{-1}$ de sementes e de $17 \mathrm{~mL}$ (P2) por $0,5 \mathrm{~kg}$ de sementes

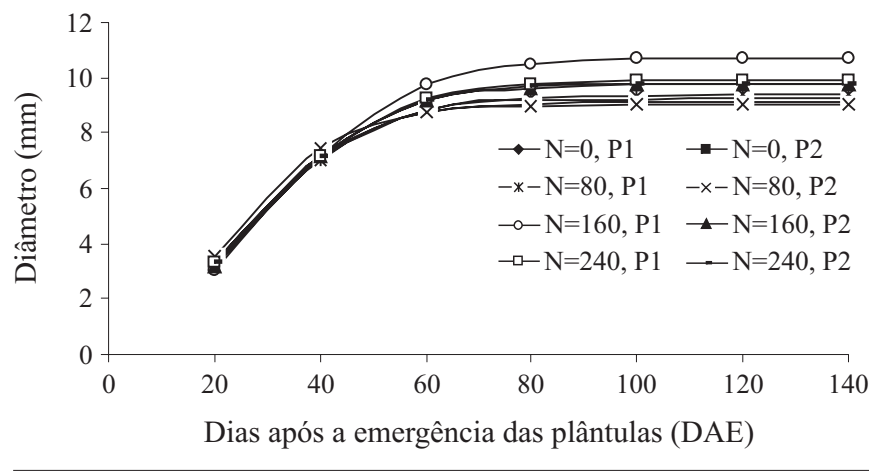

Figura 2. Diâmetro de planta em função do tempo, para as dosagens de 0 , 80,160 e $240 \mathrm{~kg} \mathrm{ha}^{-1}$ de $\mathrm{N}$ e as dosagens do Stimulate ${ }^{\circledR}$ de $10 \mathrm{~mL}$ (P1) por $0,5 \mathrm{~kg} \mathrm{ha}^{-1}$ de sementes e de $17 \mathrm{~mL}(\mathrm{P} 2)$ por $0,5 \mathrm{~kg} \mathrm{ha}^{-1}$ de sementes 
Tabela 2. Equações da altura de planta em função do tempo (dias) para cada tratamento

\begin{tabular}{|c|c|c|}
\hline Tratamentos & Modelo & $R^{2}$ \\
\hline $\begin{array}{l}\mathrm{T} 1 \text { ( } 0,0 \mathrm{~kg} \text { de } \mathrm{N}+10 \mathrm{~mL} \text { por } 0,5 \\
\mathrm{~kg} \text { de St) }\end{array}$ & $\mathrm{Y}=118,3 /\left[1+\mathrm{e}^{\left(2,6579-0,064^{*} \mathrm{x}\right)}\right]$ & 0,99 \\
\hline $\begin{array}{l}\text { T2 ( } 0,0 \mathrm{~kg} \text { de } \mathrm{N}+17 \mathrm{~mL} \text { por } 0,5 \\
\mathrm{~kg} \text { de St) }\end{array}$ & $Y=115,6 /\left[1+e^{\left(2,2155-0,0532^{\star} \times\right)}\right]$ & 0,99 \\
\hline $\begin{array}{l}\text { T3 (80 kg de N + } 10 \mathrm{~mL} \text { por } 0,5 \\
\text { kg de St) }\end{array}$ & $Y=120,6 /\left[1+e^{\left(2,6352-0,0634^{*} \times\right)}\right]$ & 0,99 \\
\hline $\begin{array}{l}\text { T4 ( } 80 \mathrm{~kg} \text { de N + } 17 \mathrm{~mL} \text { por } 0,5 \\
\mathrm{~kg} \text { de St) }\end{array}$ & $\mathrm{Y}=122,9 /\left[1+\mathrm{e}^{\left(2,5011-0,0626^{\star} \mathrm{x}\right)}\right]$ & 0,99 \\
\hline $\begin{array}{l}\text { T5 (160 kg de } \mathrm{N}+10 \mathrm{~mL} \text { por } 0,5 \\
\mathrm{~kg} \text { de St) }\end{array}$ & $\mathrm{Y}=141,5 /\left[1+\mathrm{e}^{\left(3,0194-0,0654^{*} \times\right)}\right]$ & 0,99 \\
\hline $\begin{array}{l}\text { T6 (160 kg de N + } 17 \mathrm{~mL} \text { por } 0,5 \\
\text { kg de St) }\end{array}$ & $\mathrm{Y}=137,8 /\left[1+\mathrm{e}^{\left(3,1778-0,0718^{\star} \times\right)}\right]$ & 0,99 \\
\hline $\begin{array}{l}\text { T7 (240 kg de N + } 10 \mathrm{~mL} \text { por } 0,5 \\
\text { kg de St) }\end{array}$ & $Y=126,8 /\left[1+e^{(2,7393-0,0662 * x)}\right]$ & 0,99 \\
\hline $\begin{array}{l}\text { T8 (240 kg de N + } 17 \mathrm{~mL} \text { por } 0,5 \\
\text { kg de St) }\end{array}$ & $Y=135,6 /\left[1+e^{(2,8816-0,0655 * x)}\right]$ & 0,99 \\
\hline T9 (Testemunha sem N e sem St) & $\mathrm{Y}=3 /\left[1+\mathrm{e}^{\left(2,6628 \mathrm{x}-23,489^{\star} \times\right)}\right]$ & 0,97 \\
\hline
\end{tabular}

Tabela 3. Equações de regressão do diâmetro do caule em Função do tempo para cada tratamento

\begin{tabular}{|c|c|c|}
\hline Tratamento & Modelo & $\mathbf{R}^{2}$ \\
\hline $\mathrm{T} 1(0,0 \mathrm{~kg}$ de $\mathrm{N}+10 \mathrm{ml} / 0,5 \mathrm{~kg}$ de St) & $Y=9,2198 /\left[1+e^{\left(2,4083-0,0904{ }^{*} \times\right)}\right]$ & 0,99 \\
\hline T2(0,0 kg de N+17 m/ $0,5 \mathrm{~kg}$ de St) & $\mathrm{Y}=9,12 /\left[1+\mathrm{e}^{\left(2,3887-0,0918^{\star} \times\right)}\right]$ & 0,99 \\
\hline T3 $(80 \mathrm{~kg}$ de $\mathrm{N}+10 \mathrm{~m} / 0,5 \mathrm{~kg}$ de $\mathrm{St})$ & $Y=9,3677 /\left[1+e^{(2,4332-0,0878 * x)}\right]$ & 0,98 \\
\hline $\mathrm{T} 4(80 \mathrm{~kg}$ de $\mathrm{N}+17 \mathrm{~m} / 0,5 \mathrm{~kg}$ de $\mathrm{St})$ & $\mathrm{Y}=9,0156 /\left[1+\mathrm{e}^{\left(2,4502-0,1006^{\star} \mathrm{x}\right)}\right]$ & 0,98 \\
\hline T5 (160 kg de N+10 ml/0,5 kg de St) & $Y=10,7019 /\left[1+e^{\left(2,5627-0,0820^{*} \times\right)}\right]$ & 0,99 \\
\hline T6(160 kg de N+17 ml/0,5 kg de St) & $\mathrm{Y}=9,7522 /\left[1+\mathrm{e}^{\left(2,4432-0,0865{ }^{*} \times\right)}\right]$ & 0,99 \\
\hline$\Pi(240 \mathrm{~kg}$ de $\mathrm{N}+10 \mathrm{ml} / 0,5 \mathrm{~kg}$ de $\mathrm{St})$ & $\mathrm{Y}=9,9152 /\left[1+\mathrm{e}^{(2,3494-0,0825)}\right]$ & 0,98 \\
\hline $\mathrm{T} 8(240 \mathrm{~kg}$ de $\mathrm{N}+17 \mathrm{ml} / 0,5 \mathrm{~kg}$ de St) & $\mathrm{Y}=9,7873 /\left[1+\mathrm{e}^{\left(2,3360-0,0837^{\star} \times\right)}\right]$ & 0,99 \\
\hline T9(Testemunha sem N e sem St) & $Y=-0,0009 /\left[1+e^{(0,1901 x+0,4757 * x)}\right]$ & 0,90 \\
\hline
\end{tabular}

Em outras culturas, como o arroz, o referido promotor de crescimento funcionou bem, como pode ser comprovado nos dados de Vieira (2001); entretanto, Castro et al. (1998) e Vieira (2001) encontraram efeitos significativos do Stimulate ${ }^{\circledR}$, respectivamente nas culturas da laranja pêra e do arroz.

Castro et al. (1998), efetuaram pulverização com o fertilizante foliar Micro-citros e o bioestimulante Stimulate ${ }^{\circledR}$, em pomar uniforme de laranja pêra (Citrus sinensis L. Osbeck) e observaram aumentos no número de ramos 69 dias após a primeira aplicação de Stimulate ${ }^{\circledR} 1,0 \mathrm{~L} \mathrm{ha}^{-1}$.

Vê-se, na Tabela 4, que ocorreu aumento significativo no diâmetro caulinar aos 120 dias de emergência das plantas em função da aplicação de nitrogênio.

Verificou-se que não houve efeitos significativos para nenhuma das interações entre os fatores estudados (dosagens de $\mathrm{N}$ e dosagens do promotor de crescimento aplicado nas sementes), indicando independência entre os mesmos (Tabela 5).

O promotor de crescimento, aplicado às sementes não alterou significativamente nenhuma das variáveis estudadas nem, tampouco os contrastes ortogonais entre a média do fatorial testado e a testemunha absoluta, que não recebeu o promotor de crescimento nem a adubação nitrogenada (Tabela 5).

A precocidade das plantas foi alterada para menos, à
Tabela 4. Resumo da análise de variância e valores médios das variáveis altura, diâmetro do caule e área foliar por planta, em função do tempo e das dosagens de nitrogênio e do promotor de crescimento, aos 120 dias

\begin{tabular}{|c|c|c|c|}
\hline \multirow[b]{2}{*}{ Fatores } & \multicolumn{3}{|c|}{ Variáveis } \\
\hline & $\begin{array}{l}\text { Altura } \\
\text { (cm) }\end{array}$ & $\begin{array}{l}\text { Diâmetro } \\
\text { (mm) }\end{array}$ & $\begin{array}{l}\text { Área foliar } \\
\text { por planta }\end{array}$ \\
\hline \multicolumn{4}{|l|}{ Dosagens de N (kg ha-1) } \\
\hline 0 & 116,83 & 9,48 & 1585,70 \\
\hline 80 & 122,00 & 9,23 & 1336,78 \\
\hline 160 & 136,33 & 10,53 & 1833,60 \\
\hline 240 & 129,33 & 9,77 & 1385,92 \\
\hline Teste F & $435,71^{\text {ns }}$ & $1,91^{*}$ & $306494,61^{\text {ns }}$ \\
\hline \multicolumn{4}{|l|}{$\begin{array}{l}\text { Dosagens do promotor } \\
\text { Stimulate (mL por } 0,5 \mathrm{~kg} \\
\text { de sementes) }\end{array}$} \\
\hline 10 & 125,17 & 9,96 & 1550,03 \\
\hline 17 & 127,08 & 9,55 & 1520,97 \\
\hline Teste F & $22,04^{\mathrm{ns}}$ & $1,04^{\mathrm{ns}}$ & $5069,52^{\mathrm{ns}}$ \\
\hline NXP & $62,71^{\text {ns }}$ & $0,19^{\text {ns }}$ & $720047,75^{\mathrm{ns}}$ \\
\hline Média Fatorial & 126,12 & 9,75 & 1535,5 \\
\hline Média Testemunha & 114,33 & 9,55 & 1669,26 \\
\hline Fatorial vs Test. & $370,78^{\text {ns }}$ & $0,12^{\mathrm{ns}}$ & $47713,97^{\mathrm{ns}}$ \\
\hline
\end{tabular}

medida que se elevou a dosagem de nitrogênio aplicada, independente do uso ou não do promotor do crescimento, conforme a Tabela 5 .

Tais resultados se alinham a vários outros realizados anteriormente, tanto em nível de campo quanto em casa de vegetação, visto que o nitrogênio promove o crescimento, como um todo, e então retarda o desenvolvimento, sendo este aspecto, até certo ponto antagônico, no caso de culturas que apresentam crescimento do tipo indeterminado, como o algodoeiro (Street \& Opik, 1974).

Por se tratar de uma cultivar nova lançada recentemente pela Embrapa Algodão justifica-se a ausência de respostas para o Stmulate ${ }^{\circledR}$; como se trata de um novo genótipo, não

Tabela 5. Resumo das análises de variância dos dados referentes ao crescimento e desenvolvimento

\begin{tabular}{|c|c|c|c|c|c|}
\hline \multirow[b]{2}{*}{$\begin{array}{l}\text { Fontes } \\
\text { de variação }\end{array}$} & \multirow[b]{2}{*}{ G.L } & \multicolumn{4}{|c|}{ Quadrado Médio (QM) } \\
\hline & & $\begin{array}{l}\text { Primeiro } \\
\text { Botão (dias) }\end{array}$ & $\begin{array}{l}\text { Primeira } \\
\text { Flor (dias) }\end{array}$ & $\begin{array}{c}\text { Primeiro } \\
\text { Capulho } \\
\text { (dias) }\end{array}$ & $\begin{array}{c}\text { Precocidade } \\
\text { (\%) }\end{array}$ \\
\hline Nitrogênio & 3 & $8,94^{\mathrm{ns}}$ & $7,93^{\text {ns }}$ & $23,00^{\text {ns }}$ & $0,13^{*}$ \\
\hline Linear & 1 & $0,02^{\text {ns }}$ & $0,20^{\text {ns }}$ & $0,00^{\text {ns }}$ & $0,14^{\mathrm{ns}}$ \\
\hline Quadrática & 1 & $0,33^{\text {ns }}$ & $1,69^{n s}$ & $0,75^{\text {ns }}$ & $0,01^{\mathrm{ns}}$ \\
\hline Cúbica & 1 & $13,07^{* *}$ & $10,00^{*}$ & $33,75^{\text {ns }}$ & $0,06^{\mathrm{ns}}$ \\
\hline $\begin{array}{l}\text { Promotor } \\
\text { (Stimulate) }\end{array}$ & 1 & $0,17^{\mathrm{ns}}$ & $3,38^{\mathrm{ns}}$ & $0,67^{*}$ & $0,03^{\mathrm{ns}}$ \\
\hline $\mathrm{NxP}$ & 3 & $3,17^{\mathrm{ns}}$ & $2,15^{\mathrm{ns}}$ & $13,22^{\text {ns }}$ & $0,07^{\mathrm{ns}}$ \\
\hline $\begin{array}{l}\text { Fatorial vs } \\
\text { testemunha }\end{array}$ & 1 & $0,91^{\mathrm{ns}}$ & $4,45^{\mathrm{ns}}$ & $4,74^{\mathrm{ns}}$ & $0,09^{\text {ns }}$ \\
\hline Tratamento & 8 & 4,68 & 4,76 & 14,26 & 0,08 \\
\hline Blocos & 2 & 29,4 & 38,04 & 106,81 & 0,23 \\
\hline Erro & 16 & 5,99 & 6,20 & 13,02 & 0,04 \\
\hline CV\% & - & 9,01 & 5,10 & 3,75 & 53,25 \\
\hline
\end{tabular}

ns- Não significativo; *Significativo a $5 \%$ pelo teste $\mathrm{F}$; ${ }^{*}$ Significativo a $1 \%$ pelo teste $\mathrm{F}$ 
há informações sobre seu comportamento, no tocante a uma resposta aos promotores de crescimento; desta forma faz-se necessário que novos estudos sejam realizados, testando-se dosagens diferentes, tanto em experimentos em casa-de-vegetação como em campo.

\section{CONCLUSÕES}

1. O promotor de crescimento Stimulate ${ }^{\circledR}$ não alterou o crescimento do algodoeiro herbáceo, cultivar de fibra de cor verde, quando usado nas dosagens de 10 e $17 \mathrm{~mL}$ por $0,5 \mathrm{~kg}$ de sementes, aplicadas nas sementes com diluição em água, nem interagiu com o nitrogênio aplicado no solo, em cobertura, até a dosagem de $\mathrm{N}$ de $240 \mathrm{~kg} \mathrm{ha}^{-1}$.

2. O nitrogênio na forma amoniacal, aplicado ao ambiente edáfico, em cobertura, independente do fator dosagem do promotor de crescimento, incrementou o crescimento das plantas, aumentando o diâmetro do caule aos 120 dias da emergência das plantas.

\section{LITERATURA CITADA}

Banzatto, D. A.; Kronka, S. do N. Experimentação agrícola. 3.ed. Jaboticabal: FUNEP, 1995. 247p.

Beltrão, N. E. de M. Algodão brasileiro em relação ao mundo: Situação e perspectivas. In: Beltrão, N. E. de M. O agronegócio do algodão no Brasil. Brasília: Embrapa Comunicação para Transferência de Tecnologia, 1999, v.1, p.15-27.

Carvalho, L. P. de; Beltrão, N. E. de M; de Costa, J. N. da; Andrade, F. P. de; Silva, O. R. R. F. da; Araújo, G. P. de; Alves, I. BRS Verde. Campina Grande: Embrapa/CNPA, 2002, Folder
Castro, P. R. C.; Pacheco, A. C.; Medina, C. L. Efeitos de stimulate e de micro-citros no desenvolvimento vegetativo e na produtividade da laranjeira pêra. Scientia Agrícola. Piracicaba, v.55, n.2, 7p,1998.

Castro, P. R. C.; Vieira, E. L. Aplicação de reguladores vegetais na agricultura tropical. Guaíba: Livraria e Editora Agropecuária Ltda., 2001. 132p.

CONAB - Companhia Nacional de Abastecimento. Ministério da Agricultura - Pecuária e Abastecimento - MAPA. Brasília, 2004, p.3.

EMBRAPA - Empresa Brasileira de Pesquisa Agropecuária, BRS Verde. Campina Grande: Embrapa Algodão 2002, Folder

Furlani, E. J.; \& Buzetti, S. Dosagens e momentos de aplicação de adubo nitrogenado para a cultura do algodoeiro (Gossypium hirsutum L.) IAC 225. In: Congresso Brasileiro do Algodão. 2001, São Paulo. Anais Campina Grande:EmbrapaCNPA, 2001, 719p.

Gomes, F. P. Curso de estatística experimental. 11.ed. Piracicaba: Nobel, 1985, 466p.

ICAC - International Cotton Advisory Committee. Cotton: Review of the world situation. Washington: ICAC, v.54, n.2, 2000, 22p.

SAS/STAT User's guide. In: SAS Institute. SAS Online Doc: version 8.2. Cory, 2000. CD-Rom.

Street, H. E. Öpik, H. Fisiologia das angiospermas: Crescimento e desenvolvimento. São Paulo: USP, 1974. 315p.

Vieira, E. L. Ação de bioestimulante na germinação de sementes, vigor de plântulas, crescimento radicular e produtividade de soja, feijoeiro e arroz. Piracicaba: Departamento de Ciências Biológicas, USP, 2001. Tese Doutorado

Vieira, E. L.; Castro, P. R. C. Ação de stimulante no desenvolvimento inicial de plantas de algodoeiro. Piracicaba: Departamento de Ciências Biológicas, USP, 2002. 3p. 